\title{
Cleaning and retreatment protocol for a debonded ceramic restoration
}

\author{
Juan-Luis Román-Rodríguez ${ }^{1}$, Jorge Alonso-Pérez-Barquero ${ }^{2}$, August Bruguera-Álvarez ${ }^{3}$, Rubén Agustín- \\ Panadero ${ }^{1}$, Antonio Fons-Font ${ }^{4}$
}

${ }^{1}$ DDS, MSc, PhD, Associate Lecturer, Department of Dental medicine, Prosthodontic and Occlusion Teaching Unit, University of Valencia, University of Valencia General Studies (UVGS) Spain

${ }^{2}$ DDS, Lecturer in Prosthodontics. Prosthodontic and Occlusion Teaching Unit, UVGS, Spain

${ }^{3}$ CDT, Dental Technician, Dental Design Laboratory, Barcelona, Spain

${ }^{4}$ DDS, PhD, MD, Senior Lecturer, Department of Dental medicine, Prosthodontic and Occlusion Teaching Unit, UVGS, Spain

Correspondence:

Unidad de Prostodoncia y Oclusión

Departamento de Estomatología

Edificio Clínica Odontológica

C/ Gascó Oliag N 146010

Universitat de Valencia, España

juanluis.romanrodriguez@gmail.com

\begin{abstract}
Román-Rodríguez JL, Alonso-Pérez-Barquero J, Bruguera-Álvarez A, Panadero RA, Fons-Font A. Cleaning and retreatment protocol for a debonded ceramic restoration. J Clin Exp Dent. 2015;7(1):e60-2.

http://www.medicinaoral.com/odo/volumenes/v7i1/jcedv7ilp60.pdf
\end{abstract}

Received: 22/07/2014

Accepted: 09/10/2014

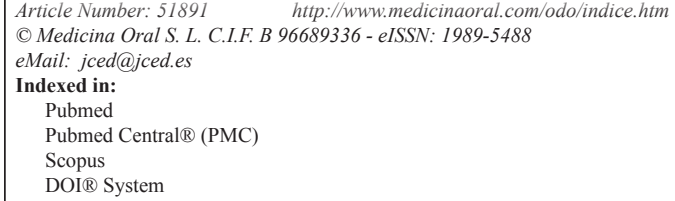

\begin{abstract}
Objectives: The aim of this article is to propose a resin cement cleaning protocol for use before recementing a debonded restoration.

Study Design: Ceramic samples were fabricated from IPS d.sign ${ }^{\circledR}$ and IPS e.max Press ${ }^{\circledR}$ and were treated with hydrofluoric acid etching (HF), or $\mathrm{HF}+$ silane $(\mathrm{S})$, or $\mathrm{HF}+\mathrm{S}+$ adhesive or $\mathrm{HF}+\mathrm{S}+\mathrm{A}+$ resin cement. All samples were placed in a furnace at $650^{\circ}$ for one minute in order to attempt to pyrolyze the composite. Each step was examined under scanning electron microscopy (SEM).

Results: When the cleaning protocol had been performed, it left a clean and retentive surface.

Conclusions: If the restoration is placed in a furnace at $650^{\circ}$ for one minute, the composite cement will burn or pyrolyze and disappear, allowing conventional retreatment of the ceramic before rebonding.
\end{abstract}

Key words: Ceramic, debond, surface treatment.

\section{Introduction}

Cementing ceramic restorations requires a bonding technique and a resin luting cement. If the restoration debonds, the remains of the adhesive must be eliminated from the restoration before repeating the conventional bond procedure: conditioning with hydrofluoric acid, application of a silane coupling agent, adhesive and resin cement. The debond rate of ceramic restorations may be as high as $9 \%$ (1). When a restoration debonds, the resin cement almost always remains adhered to it (2) (Fig.
1). This must be removed before the restoration can be recemented $(3,4)$. The aim of this article is to propose a resin cement cleaning protocol for use before recementing a debonded restoration.

\section{Material and Methods}

Ceramic samples $(n=10)$ were fabricated $(3 \times 3 \times 1 \mathrm{~mm})$ from IPS d.sign ${ }^{\circledR}$ and IPS e.max Press ${ }^{\circledR}$, (Ivoclar Vivadent, Schaan, Liechtenstein). Two samples were excluded from surface treatment. One sample of each ceramic was 


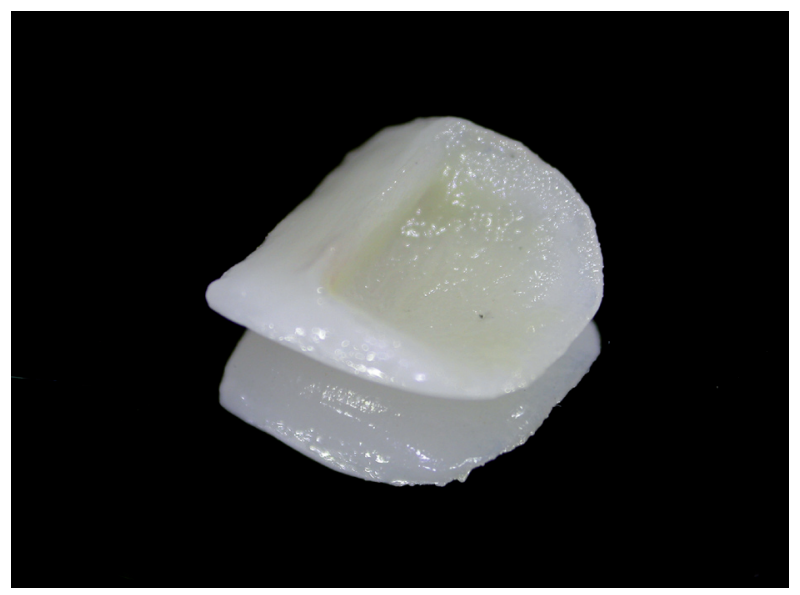

Fig. 1. Debonded ceramic restoration.

treated with hydrofluoric acid etching (HF), another pair with $\mathrm{HF}+$ silane $(\mathrm{S})$, one pair with $\mathrm{HF}+\mathrm{S}+$ adhesive and the last pair with $\mathrm{HF}+\mathrm{S}+\mathrm{A}+$ resin cement. All samples were placed in a furnace at $650^{\circ}$ for one minute in order to attempt to pyrolyze the composite. Each step was examined under scanning electron microscopy (SEM).

\section{Results}

Etching with HF brought about a change to the ceramic surface, which passed from having an almost completely smooth surface texture (Fig. 2a) or irregular pressed surface (Fig. 3a) to a highly anfractuous and retentive surface, with numerous hollows into which the resin cement could penetrate and so remain retained when set (Figs. 2b, 3b). After applying silane, adhesive and cement, the surface appeared smooth and only the resin remained visible (Figs. $2 \mathrm{c}, 3 \mathrm{c})$. When the cleaning protocol had been performed, it left a clean and retentive surface (Figs. 2d, 3d).

\section{Discussion}

The two ceramic surfaces investigated differed as a result of their fabrication techniques5 (IPS d.sign: layering technique; IPS e.max Press: pressure injection) (Figs. 2a, 3a). HF etching produced different patterns due to the two ceramics' different compositions, (5) although in both cases a highly retentive surface was produced for bonding (Figs. 2b, 3b). This was eliminated after heating in the furnace because the composite's melting point is lower than that of ceramic.

A ceramic restoration that has debonded must be placed in the furnace at $650^{\circ}$ for one minute to burn away the remaining resin cement before conventional mechanical (HF) and chemical (silane, adhesive and cement) treatment is performed. In this way, the restoration can be rebonded obtaining maximum ceramic adhesion. (Table 1).
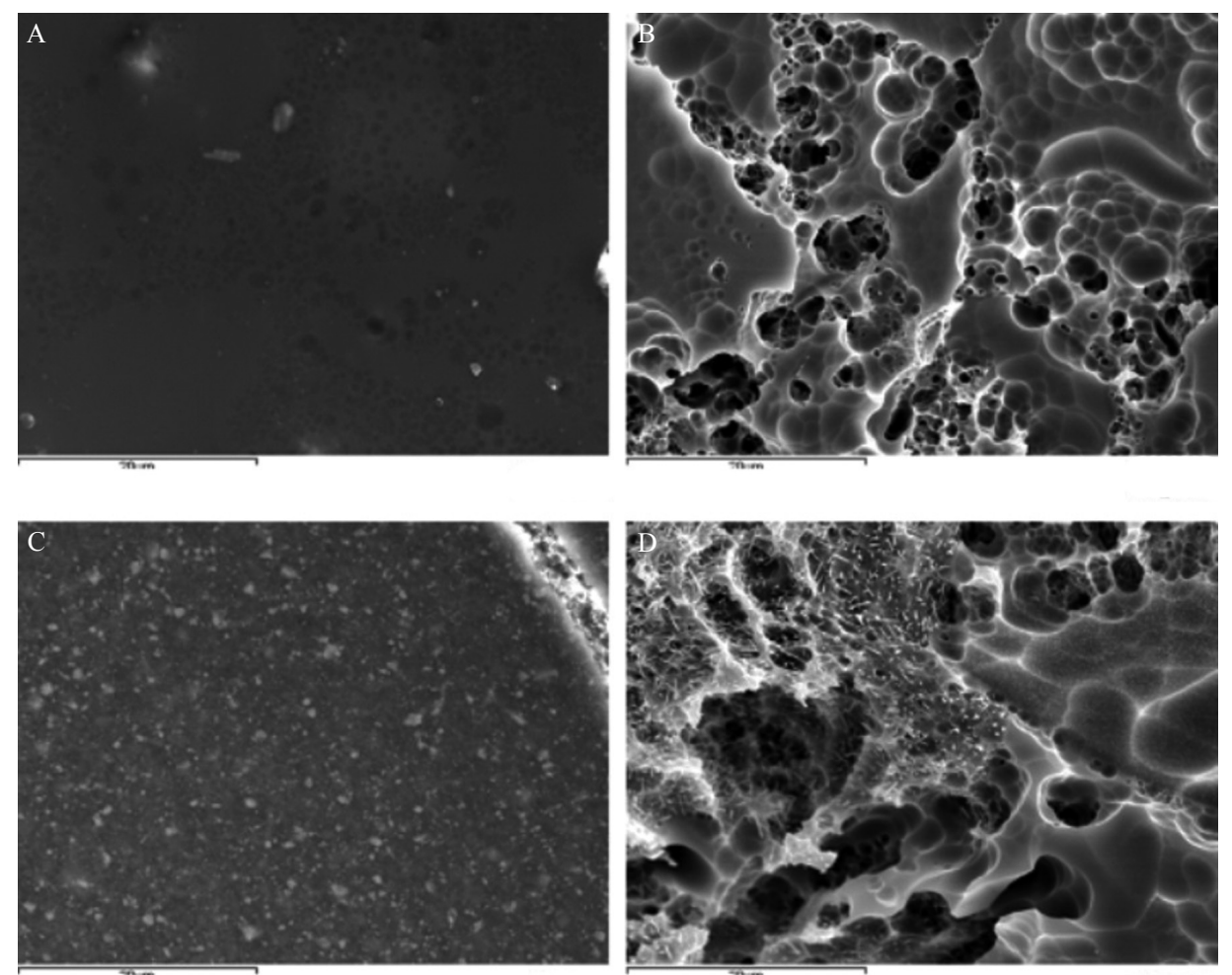

Fig. 2. A) IPS d.sign (2500x); B) IPS d.sign HF 9.6\% for 2 minutes (2500x); C) After silane coupling agent, adhesive and resin cement application (2500x); D) Placed in furnace for 1 minute and then etched with $9.6 \%$ HF for 2 minutes (2500x). 

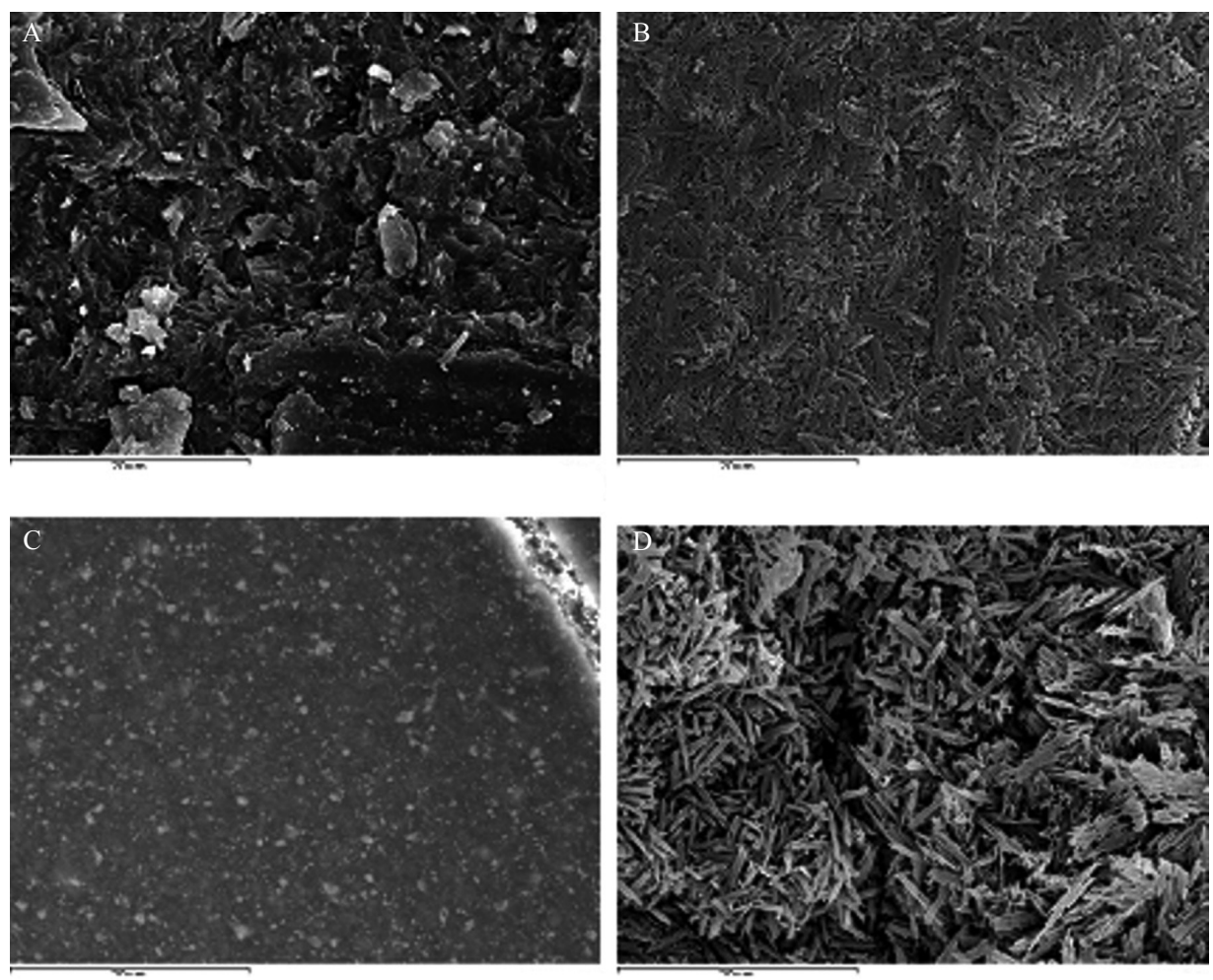

Fig. 3. A) IPS e.max Press (2500x); B) IPS e.max Press $+4.9 \%$ HF for 20 seconds (2500x); C) Composite cement surface (2500x); D) When the cement has been burned away it is re-etched with $4.9 \%$ HF for 20 seconds (2500x).

Table 1. Cleaning and retreatment protocol for debonded ceramic restoration.

\begin{tabular}{|c|c|}
\hline LABORATORY & CLINIC \\
\hline $\begin{array}{l}\text { 1. The ceramic restoration is sent to the laboratory and a } \\
\text { provisional restoration fabricated. }\end{array}$ & $\begin{array}{l}\text { 1. Etched with } 4.9 \% \text { HF for } 20 \text { seconds (for high resistance } \\
\text { silicates) or } 9.6 \% \mathrm{HF} \text { (for feldspathic ceramics) for } 2 \text { minu- } \\
\text { tes, washed and dried. }\end{array}$ \\
\hline 2. Furnace at $650^{\circ}$ for 1 minute. & $\begin{array}{l}\text { 2. Etched with } 37 \% \text { orthophosphoric acid for } 1 \text { minute, rin- } \\
\text { sed and dried. }\end{array}$ \\
\hline $\begin{array}{l}\text { 3. Sandblasted with } 50 \text {-micron glass beads at } 1.5-2 \mathrm{~kg} \\
\text { pressure (maximum). }\end{array}$ & $\begin{array}{l}\text { 3. Ultrasound distilled water bath for } 5 \text { minutes followed } \\
\text { by drying. }\end{array}$ \\
\hline 4. Steam cleaning. & 4. Silane coupling agent for 1 minute and heat application. \\
\hline 5. Restoration sent back to clinic. & 5. Adhesive without polymerization. \\
\hline
\end{tabular}

\section{References}

1. Granell Ruíz M, Agustín Panadero R, Fons Font A, Román Rodríguez JL, Solá Ruíz MF. Influence of bruxism on survival of porcelain laminate veneers. Med Oral Patol Oral Cir Bucal. 2014;19:e426-32. 2. Blatz MB, Sadan A, Kern M. Resin-ceramic bonding: a review of the literature. J Prosthet Dent. 2003;89:268-74.

3. Magne P, Cascione D. Influence of post-etching cleaning and con- necting porcelain on the microtensile bond strength of composite resin to feldspathic porcelain. J Prosthet Dent. 2006;96:354-61.

4. Martins ME, Leite FP, Queiroz JR, Vanderlei AD, Reskalla HN, Ozcan M. Does the ultrasonic cleaning medium affect the adhesion of resin cement to feldspathic ceramic? J Adhes Dent. 2012;14:507-9.

5. Duarte Jr. S, Phark J-H, Blatz M, Sadan A. Biomaterials Update Ceramic Systems: An Ultrastructural Study. QDT. 2010;33:42-60. 